\title{
Digestibilidad de hidrolizados enzimáticos de vísceras de origen animal en Piaractus brachypomus, Cuvier 1818*
}

\section{Digestibility of enzymatic hydrolyzates from animal origin viscera in Piaractus brachypomus, Cuvier 1818}

\begin{abstract}
PEREA-ROMÁN, CRÍSPULO ${ }^{1 *}$; GARCES-CAICEDO, YENY-JUDITH ${ }^{2}$; MORALES-BRAVO, YERIKA-JESLANNY;
\end{abstract} JIMENEZ-CHAMORRO, MARLY-ANDREINA4; HOYOS-CONCHA, JOSÉ-LUÍS5; VIVAS-QUILA, NELSON-JOSÉ ${ }^{6}$

Historial del Artículo

Recibido para evaluación: 28 septiembre 2020.

Aprobado para publicación: 2 marzo 2021.

* $\quad$ Proyecto de investigación de origen: "Aprovechamiento de vísceras de pollo mediante hidrólisis enzimática como alternativa nutricional en piscicultura de aguas cálidas". Financiación: MINCIENCIAS con recursos provenientes del patrimonio autónomo fondo nacional de financiamiento para la ciencia, la tecnología y la innovación Francisco José de Caldas. Culminación: 17 de mayo de 2019 al 17 de noviembre de 2021.

1 Universidad del Cauca, Departamento de Ciencias Agropecuarias, Facultad de Ciencias Agrarias, grupos de investigación ASUBAGROIN y NUTRIFACA. Doctor en Ciencias Agrarias. Popayán, Colombia. https://orcid.org/0000-0002-9604-4264

2 Universidad del Cauca, Departamento de Ciencias Agropecuarias, Facultad de Ciencias Agrarias, grupos de investigación ASUBAGROIN y NUTRIFACA. Magíster en Ciencias Agrarias. Popayán, Colombia. https://orcid.org/0000-0002-0491-3347

3 Universidad del Cauca, Departamento de Ciencias Agropecuarias, Facultad de Ciencias Agrarias, grupos de investigación ASUBAGROIN y NUTRIFACA. Ingeniera Agropecuaria. Popayán, Colombia. https://orcid.org/0000-0002-9669-9295

4 Universidad del Cauca, Departamento de Ciencias Agropecuarias, Facultad de Ciencias Agrarias, grupos de investigación ASUBAGROIN y NUTRIFACA. Ingeniera Agropecuaria. Popayán, Colombia. https://orcid.org/0000-0002-6610-7228

5 Universidad del Cauca, Departamento de Agroindustria, Facultad de Ciencias Agrarias, grupo de investigación ASUBAGROIN. Doctor en Ingeniería de Alimentos. Popayán, Colombia. http://orcid.org/0000-0001-9025-9734

6 Universidad del Cauca, Departamento de Ciencias Agropecuarias, Facultad de Ciencias Agrarias, grupo de investigación NUTRIFACA. Doctor en Ciencias Agrarias. Popayán, Colombia. https://orcid.org/0000-0003-0165-2863

\footnotetext{
*Correspondencia: e-mail: cproman@unicauca.edu.co; cperear@unal.edu.co
} 


\section{RESUMEN}

La alimentación representa el rubro principal en la producción piscícola, por lo anterior, se evaluó la digestibilidad mediante principio de aditividad de hidrolizados enzimáticos de origen animal en Cachama blanca (Piaractus brachypomus) como alternativa nutricional. Para ello, se utilizó una dieta control y tres mezclas, en las mezclas se sustituyó el $30 \%$ de la dieta control por hidrolizado de vísceras de pollo, cerdo y trucha respectivamente, las cuales se suministraron a 120 cachamas con peso promedio de 145,40 $\pm 3,17 \mathrm{~g}$, los peces fueron distribuidos mediante un diseño completamente al azar (DCA) en 12 tanques cilindro cónicos y se sometieron a colecta de heces para determinación de la digestibilidad de nutrientes, energía y la absorción de minerales. Se presentaron diferencias significativas $(p<0,05)$ para la digestibilidad aparente de proteína cruda, energía bruta, fibra cruda, absorción de cenizas, calcio, fósforo y energía digestible de acuerdo al tipo de hidrolizado evaluado y en relación con la dieta control. Los resultados evidenciaron que los hidrolizados presentan alto valor nutricional debido a que la digestibilidad de nutrientes y la energía fueron superior al $80 \%$, por consiguiente, los hidrolizados enzimáticos de vísceras de origen animal constituyen una alternativa proteica y energética en la alimentación de peces.

\section{ABSTRACT}

Feeding represents the core business in fish production, therefore, digestibility was evaluated by a principle of additivity of enzymatic hydrolyzates from animal origin in White Cachama (Piaractus brachypomus) as a nutritional alternative. For this purpose, we used a control diet and three mixtures. In the case of mixtures, $30 \%$ of the control diet was replaced by hydrolyzed chicken, pork and trout viscera respectively; which were supplied to 120 juveniles of white Cachama with an average weight of $145,40 \pm 3,17 \mathrm{~g}$, fish were distributed by means of a complete randomized design (DCA) in 12 conical cylinder tanks and were collected for stool by sedimentation to determine the digestibility of nutrients, energy and mineral absorption. Significant differences $(p<0,05)$ were presented for the apparent digestibility of crude protein, crude energy, crude fiber, absorption of ash, calcium, phosphorus and digestible energy according to the type of enzymatic hydrolyzates evaluated and in relation to the control diet. The results showed that the hydrolyzates have a high nutritional value because

\section{PALABRAS CLAVE:}

Alternativa nutricional; Principio de aditividad; Vísceras de pollo; Vísceras de cerdo; Vísceras de trucha; Cachama blanca; Hidrólisis; Digestibilidad aparente; Alimento proteico; Alimento energético.

\section{KEYWORDS:}

Nutritional alternative; Additivity principle; Chicken viscera; Pig viscera; Trout viscera; White cachama; Hydrolysis, Apparent digestibility; Protein food; Energy food.

\footnotetext{
Cómo citar este artículo: PEREA-ROMÁN, CRÍSPULO; GARCES-CAICEDO, YENY-JUDITH; MORALES-BRAVO, YERIKA-JESLANNY; JIMENEZCHAMORRO, MARLY-ANDREINA; HOYOS-CONCHA, JOSÉ-LUÍS; VIVASQUILA, NELSON-JOSÉ. Digestibilidad de hidrolizados enzimáticos de vísceras de origen animal en Piaractus brachypomus, Cuvier 1818. Biotecnología en el sector agropecuario y agroindustrial, v. 20, n. 1, 2022, p. 54-67. Doi: https:// doi.org/10.18684/rbsaa.v20.n1.2022.1606
} 
the digestibility of nutrients and energy were greater than $80 \%$. Therefore, enzymatic hydrolyzates from animal viscera are a protein and energy alternative in fish feed.

\section{INTRODUCCIÓN}

La acuicultura genera más de 51.308 empleos directos, 153.923 empleos indirectos y contribuye con el 0,19\% del producto interno bruto (PIB) en Colombia. Para el año 2019, la producción piscícola en Colombia alcanzó las 165.444 t, de la cuales, la cachama aporta el 19 \% según el Ministerio De Agricultura Y Desarrollo Rural (MADR, 2020). El departamento del Cauca cuenta con potencial para el desarrollo de la acuicultura, en especial la producción de Cachama blanca, sin embargo, el elevado precio de los concentrados ha limitado su producción.

En el sector piscícola, entre las mayores limitantes está la baja disponibilidad de materias primas de alta calidad para producción de concentrado tanto proteica como energética, debido a que representan entre 67 y $70 \%$ del costo operacional; además, la falta de conocimiento de la digestibilidad de los nutrientes y energía de los alimentos, han desencadenado problemas en este sector, ya que en los últimos años su rentabilidad y crecimiento han venido disminuyendo; por esto, se hace necesario buscar alternativas nutricionales regionales más económicas, que puedan ser utilizadas en el balance de dietas para peces (Perea et al., 2018; Corrêa et al., 2020).

Una importante cantidad de residuos que corresponden a vísceras blancas son generados en el procesamiento de Trucha arcoíris, pollo de engorde y porcinos con 13,0, 9,5 y 4,15\% respectivamente, los que no están siendo aprovechados y su disposición inadecuada genera considerables impactos ambientales (Wei et al., 2020; Dos santos et al., 2021). Una solución es la utilización de estos residuos a través de la fabricación de hidrolizados o ensilajes que pueden ser utilizados en la formulación de dietas para la alimentación de peces, ya que presenta un alto contenido nutricional tanto proteico como energético (Banze et al., 2017). Sin embargo, es importante conocer como los peces pueden aprovechar los nutrientes y la energía que presentan estas alternativas nutricionales usando, por ejemplo, la técnica de digestibilidad aparente para conocer y cuantificar la cantidad de nutrientes disponibles y que el animal es capaz de digerir (Perea et al., 2017).

El uso de hidrolizados como alternativa nutricional en piscicultura se debe principalmente a la necesidad de encontrar materias primas con alto valor nutritivo y biológico; además de su contribución en la disminución de los costos de producción y en la reducción de los efectos adversos en el medio ambiente (Perea et al., 2018). Alrededor del mundo se han realizado diversos estudios con subproductos de origen animal como son vísceras de pescado, aves y cerdo para la alimentación de muchas especies animales, principalmente en especies menores (Banze et al., 2017; Montoya et al., 2017; Tanuja et al., 2017), un ejemplo de ello es el estudio realizado con harina de subproductos avícolas en la alimentación de lubina europea (Dicentrarchus labrax) (Campos et al., 2018), también el uso de ensilado ácido de pescado en pacu (Piaractus mesopotamicus) y tambacu (Colossoma macropomum $\times$ Piaractus mesopotamicus) (Corrêa et al., 2020); además, la inclusión de harina de ensilado biológico de desechos de pescado (tambaqui) en aves de postura (Guimarães et al., 2019) y el uso de harina de ensilado carníco en Clarias gariepinus (Llanes et al., 2017).

Por lo anterior, se evaluaron tres hidrolizados de vísceras de origen animal (trucha, cerdo y pollo) en la alimentación de juveniles de Cachama blanca (Piaractus brachypomus) en fase de engorde donde hay mayor consumo de alimento y, por ende, mayores costos en la alimentación, mediante la determinación de la digestibilidad aparente de nutrientes (materia seca, proteína cruda, extracto etéreo y fibra cruda), absorción aparente de los minerales (cenizas, calcio, fósforo), digestibilidad de la energía bruta y energía digestible de cada uno de los hidrolizados, para destacar su potencial nutricional como alternativa en la alimentación piscícola. 


\section{MÉTODO}

A continuación, se describen los materiales y métodos que se utilizaron para la evaluación de la digestibilidad aparente de hidrolizados de origen animal en la alimentación de Cachama blanca.

\section{Localización}

El estudio se llevó a cabo en la caseta de bioensayos en peces del laboratorio de Biotecnología de la Facultad de Ciencias Agrarias de la Universidad del Cauca, localizado en la vereda las Guacas del municipio de Popayán, Cauca entre los $02^{\circ} 45^{\prime} 08,91^{\prime \prime}$ Latitud Norte y $76^{\circ} 55^{\prime} 10,86^{\prime \prime}$ Longitud Oeste, a una altura promedio de 1.737 msnm, temperatura promedio de $19^{\circ} \mathrm{C}$ y precipitación de $1.800 \mathrm{~mm}$ anuales.

\section{Material biológico}

En la investigación se utilizaron vísceras de Trucha arcoíris (Oncorhynchus mykiss), de pollos de engorde (Gallus domesticus L.) e intestinos de cerdo (Sus scrofa domesticus), las cuales fueron obtenidas de plantas de sacrificio locales, con el fin de garantizar el estado sanitario y de frescura necesarios para la preparación de los hidrolizados. En el ensayo se utilizaron 120 juveniles monosexo de Cachama blanca con un peso promedio de 145,40 $\pm 3,17$ $\mathrm{g}$, los cuales fueron suministrados por una piscifactoría local garantizando así un adecuado estado sanitario.

\section{Preparación de los hidrolizados y las mezclas}

Para la preparación de los hidrolizados, a la matriz hidrolizado de vísceras de trucha HVT (100 \% de vísceras enteras de trucha), hidrolizado de vísceras de pollo HVP (80\% de vísceras blancas de pollo enteras $+20 \%$ de vísceras de trucha enteras), hidrolizado de vísceras de cerdo HVC (70 \% de vísceras blancas de cerdo molidas + $30 \%$ de vísceras de trucha enteras), se le adicionaron $2,5 \%$ ácido fórmico al $85 \%$ p/v, 0,25 \% benzoato de sodio y 0,1 $\%$ butilhidroxitolueno - $\mathrm{BHT}$; posteriormente, los tratamientos se mezclaron para iniciar el proceso de hidrólisis y se almacenaron en recipientes plásticos cerrados en proporciones de $40 \mathrm{~kg}$, con un espacio de cabeza del $30 \%$ (Perea et al., 2017), a temperatura ambiente, durante 12 días para HVT - HVP y 18 días de almacenamiento para HVC, tiempo en el cual finaliza la hidrólisis y se obtiene un producto estable química y nutricionalmente. En el HVP y HVC las vísceras de trucha se adicionaron para acelerar el proceso de hidrólisis, debido a la baja actividad enzimática en que presentan las vísceras de pollo y los intestinos de cerdo.

Para la evaluación de la digestibilidad de los hidrolizados mediante el principio de aditividad o método de sustitución (Cho et al., 1982), se utilizó una dieta control TO (sin inclusión de hidrolizados de origen animal) y tres mezclas a las cuales se le adicionaron hidrolizados como se describe a continuación: para el tratamiento T1 (70 \% de T0 + 30\% de HVT), para el T2 (70 \% de T0 + $30 \%$ de HVP) y para el T3 (70\% de T0 + $30 \%$ de HVC) (Cuadro 1).

Para la preparación de la dieta y las mezclas, todas las materias primas (harina de pescado, torta de soya, harina de maíz amarillo, mogolla de trigo, harina de yuca, harina de trigo, aceite vegetal, entre otras) fueron pasadas por un tamiz de $425 \mu \mathrm{m}$ y se homogenizaron en una mezcladora SIMAG SM-401 durante 20 minutos. Posteriormente, se agregaron los restantes ingredientes, el óxido crómico- $\mathrm{Cr}_{2} \mathrm{O}_{3}$ a razón del $1 \%$ del total formulado y se continuó mezclado durante 30 minutos, para su posterior extrusión a $123^{\circ} \mathrm{C}$ en un extrusor doble tornillo marca Hake Polylab, obteniendo pellets de $5 \mathrm{~mm}$ de longitud, $4,5 \mathrm{~mm}$ de diámetro y entre 8 y $10 \%$ de humedad (Perea et al., 2017). 
Cuadro 1. Composición nutricional de la dieta y de los hidrolizados evaluados ( $\mathrm{g} \mathrm{kg}^{-1}$ peso seco).

\begin{tabular}{|c|c|c|c|c|}
\hline Ingredientes & TO & T1 & T2 & T3 \\
\hline Harina de pescado & 222 & \multirow{15}{*}{700} & \multirow{15}{*}{700} & \multirow{15}{*}{700} \\
\hline Harina de trigo & 39 & & & \\
\hline Salvado de maíz & 160 & & & \\
\hline Harina de yuca & 81,1 & & & \\
\hline Torta de soya & 140 & & & \\
\hline Harina de maíz amarillo & 90 & & & \\
\hline Mogolla de trigo & 151,9 & & & \\
\hline Aceite vegetal & 4,99 & & & \\
\hline Fosfato bicálcico & 8,8 & & & \\
\hline Biomix $^{1}$ & 20 & & & \\
\hline DL-metionina & 3,9 & & & \\
\hline Triptófano & 3,4 & & & \\
\hline Carboximetilcelulosa & 10 & & & \\
\hline Sal & 10 & & & \\
\hline Oxido crómico- $\mathrm{Cr}_{2} \mathrm{O}_{3}$ & 10 & & & \\
\hline $\begin{array}{l}\text { Hidrolizado de residuos de animales }\left(\mathrm{HVT}^{2}, \mathrm{HVP}^{3} \text { y } \mathrm{HVC}^{4} \text {, }\right. \\
\text { respectivamente) }\end{array}$ & 0,0 & 300 & 300 & 300 \\
\hline Total & 1000 & 1000 & 1000 & 1000 \\
\hline \multicolumn{5}{|c|}{ Composición nutricional ( $\mathrm{g} \mathrm{kg}^{-1}$ peso seco) } \\
\hline Variable & Dieta control & HVT & HVT & HVC \\
\hline Proteína cruda & 262 & 249,8 & 268,6 & 261,1 \\
\hline Extracto etéreo & 94 & 595 & 485,2 & 509,5 \\
\hline Fibra cruda & 23 & 1,4 & 5,2 & 3,1 \\
\hline Cenizas & 102 & 6,6 & 44,9 & 26,3 \\
\hline Energía digestible $(\mathrm{kcal} / \mathrm{kg})^{5}$ & 3101 & 6897,1 & 6032,3 & 6347,6 \\
\hline Calcio & 15 & 10,4 & 4 & 5,5 \\
\hline Fósforo & 10 & 34,0 & 18,2 & 15,5 \\
\hline
\end{tabular}

${ }^{1}$ Premezcla de vitaminas, minerales y aditivos - Biomix S.AC) (Composición por kilogramo de producto): Vitamina A (800.000 UI); vitamina D3 (300.000 UI); vitamina E (11,0 g); vitamina K (2,2 g); vitamina B12 (0,01 g); tiamina (0,6 g); riboflavina (3,6 g); piridoxina (5,6 g); biotina (0,08 g); ácido pantoténico (6,8 g); niacina (5,6 g); ácido fólico (1,0 g); vitamina C (25,0 g); cloruro de colina (70,0 g); yodo (0,3 g); selenio (0,05 g); hierro (6,0 g); cobre (1,2 g); zinc (16,0 g); manganeso (7,0 g); cobalto (0,1 g); Antioxidante (30,0 g). ${ }^{2} \mathrm{HVT}$ (100\% de vísceras enteras de trucha). ${ }^{3} \mathrm{HVP}$ (80 \% de vísceras blancas de pollo enteras $+20 \%$ de vísceras enteras de trucha). ${ }^{4} \mathrm{HVC}$ (70 \% de vísceras blancas de cerdo molidas $+30 \%$ de vísceras de trucha enteras). ${ }^{5} \mathrm{ED}(\mathrm{Kcal} / \mathrm{Kg} \mathrm{MS})=4151-(122 * \%$ Cen $)+(23 * \%$ $\mathrm{PB})+(38 * \% E)-\left(64^{*} \mathrm{FC}\right)$.

\section{Determinación de la digestibilidad in vivo de los hidrolizados}

Se evaluó la digestibilidad aparente de la Materia Seca (DAMS), Proteína Cruda (DAPC), Extracto Etéreo (DAEE), Fibra Cruda (DAFC), Energía Bruta (DAEB), Absorción de Cenizas (AACEN), Absorción de Calcio (AACa), Absorción de Fósforo (AAP) y Energía Digestible Aparente (EDA), para lo cual los peces fueron evaluados en 12 tanques cilindro cónicos con capacidad de $250 \mathrm{~L}$ de volumen útil, incorporando 10 animales en cada uno, provistos de termostatos para mantener la temperatura en $26^{\circ} \mathrm{C}$, semejando las condiciones del agua de la piscifactoría donde se obtuvieron los peces; las heces se recolectaron una vez al día (7:00 h), por sedimentación a través del retiro de colectores adaptados en la parte inferior cónica de los tanques durante 20 días. Las heces húmedas recolectadas se centrifugaron a $4.500 \mathrm{rpm}$ durante 20 minutos, posteriormente fueron empacadas en bolsas plásticas con cierre hermético y se almacenaron en un congelador a $-18^{\circ} \mathrm{C}$ (Puerta et al., 2017).

A la dieta control, mezclas y muestras de heces se les determinó el contenido de Materia Seca (AOAC, 1990), Cenizas (AOAC, 1990), Proteína Cruda (Kjeldahl, 1883), Extracto Etéreo (AOAC, 1990), Fibra Cruda (AOAC, 1990), Energía Bruta con bomba calorimétrica de chaqueta CAL2k $($, Calcio (AOAC, 2005) y Fósforo (AOAC, 1990). La cuantificación del óxido crómico se realizó por espectrofotometría de absorción atómica. La digestibi- 
lidad de nutrientes y de los hidrolizados se determinó a través de las ecuaciones 1 y 2 , como lo plantea Austreng (1978) y Cho et al. (1982) y la energía digestible aparente usando la ecuación 3 según Hidalgo y Valerio (2020).

$$
\begin{aligned}
& \text { Digestibilidad de nutrientes }(\%)=100-100\left(\frac{\% \mathrm{Cr}_{2} \mathrm{O}_{3} \text { en la mezcla }}{\% \mathrm{Cr}_{2} \mathrm{O}_{3} \text { en las heces }} \times \frac{\% \text { Nutrientes en las heces }}{\% \text { Nutrientes en la mezcla }}\right) \\
& \text { Digestibilidad de hidrolizados }(\%)=\left(\frac{\text { Digestibilidad de la mezcla-(Digestibilidad del control * \% inclusión del control) }}{\% \text { inclusión del hidrolizado }}\right)
\end{aligned}
$$

Energía digestible aparente $(E D A)=($ Energía bruta $) \times(\%$ de digestibilidad de la energía $)$

\section{Plan de manejo}

Antes de la evaluación, los tanques, pisos, paredes y equipos fueron lavados y desinfectados con hipoclorito de sodio a razón de 100 ppm. Para el tratamiento profiláctico se preparó una mezcla de azul de metileno en concentración de $0,05 \mathrm{~g} \mathrm{~L}^{-1}$ de agua, de esta solución se adicionaron $100 \mathrm{~mL}$ en cada tanque durante cinco días y se realizó un recambio de agua a razón de 80 \% día (Perea et al., 2017). Durante la evaluación se llevaron registros de recolección de heces, temperatura, consumo de alimento y biometría. La dieta y las mezclas extruidas se almacenaron en recipientes plásticos con tapa para evitar humedad. Los peces fueron alimentados tres veces al día (8:00 h, 12:00 h y 16:00 h), hasta la saciedad aparente (Perea et al., 2018) y su manejo se realizó teniendo en cuenta lo estipulado en la ley 84 de 1989, en la cual se adopta el estatuto de protección de los animales para investigación en Colombia.

La calidad fisicoquímica del agua fue monitoreada cada 15 días por la metodología NANOCOLOR ${ }^{\circledR}$ con el PHOTOMETER PF-11, verificando su cumplimiento de acuerdo con los requerimientos de la especie. Los parámetros evaluados fueron oxígeno disuelto, $\mathrm{pH}$, alcalinidad de carbonatos, demanda química de oxígeno, demanda biológica de oxígeno, amonio, nitritos y nitratos, también la temperatura con un termómetro digital de punzón.

\section{Diseño experimental y análisis estadístico}

Para la evaluación de la digestibilidad aparente de cada uno de los nutrientes se utilizó un diseño completamente al azar (DCA), evaluando cuatro tratamientos, tres mezclas con inclusión de hidrolizados de residuos animales (T1, T2 y T3) y la dieta control (T0) sin inclusión de hidrolizado; cada tratamiento contó con tres réplicas y cada réplica se tomó como una unidad experimental. Cada una de las variables fue analizada mediante la aplicación de un análisis de varianza $(p<0,05)$ aplicando el test de Duncan (1975) para la comparación de las medias, tomando un valor de $(\boldsymbol{\alpha}<0,05)$ como diferencia significativa para destacar cuál o cuáles de los tratamientos presentaron un mejor comportamiento, empleando el programa SAS (Statiscal Analysis Sistem) versión 9,4.

\section{RESULTADOS}

Durante el periodo de evaluación, la sobrevivencia fue del $100 \%$, las condiciones fisicoquímicas del agua estuvieron acordes con las necesidades de la especie estudiada (Ramírez et al., 2019); la temperatura promedio del agua registrada fue de $26,4 \pm 0,7^{\circ} \mathrm{C} ; \mathrm{pH}$ de $6,8 \pm 0,0$; oxígeno disuelto $5,1 \pm 0,0 \mathrm{mg} \mathrm{L}^{-1}$; demanda química de oxígeno (DQO) y demanda biológica de oxígeno $\left(\mathrm{DBO}_{5}\right)$ de $1,5 \pm 0,0$ y $3,98 \pm 0,1 \mathrm{mg} \mathrm{L}^{-1}$ respectivamente; la alcalinidad de carbonatos fue de $0,9 \mathrm{mmol} \mathrm{L}^{-1} \pm 0,0 ;$ nitritos $0,1 \pm 0,0 \mathrm{mg} \mathrm{L}^{-1}$; nitratos de $0,6 \mathrm{mg} \mathrm{L}^{-1}$ y el amonio $1,3 \pm 0,2 \mathrm{mg} \mathrm{L}^{-1}$. 


\section{Caracterización fisicoquímica y microbiológica de los hidrolizados}

Los resultados obtenidos del seguimiento fisicoquímico y microbiológico de los hidrolizados se presentan en el Cuadro 2.

Cuadro 2. Caracterización fisicoquímica y microbiológica de los hidrolizados de vísceras de pollo, cerdo y trucha.

\begin{tabular}{|l|c|c|c|}
\hline \multicolumn{1}{|c|}{ Variable } & Hidrolizado de pollo & Hidrolizado de cerdo & Hidrolizado de trucha \\
\hline $\mathrm{pH}$ & $3,37 \pm 0,03$ & $3,16 \pm 0,01$ & $3,51 \pm 0,11$ \\
\hline Acidez titulable (\%) & $3,37 \pm 0,13$ & $3,55 \pm 0,06$ & $3,16 \pm 0,26$ \\
\hline Consistencia (cm/30 s) & $17,9 \pm 0,12$ & $10,3 \pm 0,2$ & $30,0 \pm 0,0$ \\
\hline Mesófilos aerobios (UFC1/g) & 0,0 & 0,0 & 0,0 \\
\hline Mohos y levaduras (UFC/g) & 0,0 & 0,0 & 0,0 \\
\hline Coliformes totales (NMP2/g) & 0,0 & 0,0 & 0,0 \\
\hline
\end{tabular}

${ }^{1}$ UFC: Unidades Formadora de Colonia. ${ }^{2}$ NMP: Número Más Probable.

Los resultados obtenidos DEI pH fueron inferiores a 4,0 lo que permite la estabilidad del producto evitando el deterioro por la acción de microrganismos indeseables que generan putrefacción, garantizando un proceso adecuado de hidrólisis (Hoyos et al., 2018). Los valores presentados en este estudio fueron inferiores a los encontrados por Llanes et al. (2019) con ensilado cárnico con valores de 4,7 y similares a los evaluados por Perea et al. (2017) con ensilaje de residuos de trucha para alimentación animal con valores de 3,26 y a los citados por Ozyurt et al. (2020) en ensilaje ácido de residuos de peces con 3,82 e inferiores a los citados por Bringas et al. (2018) en ensilado de subproductos de tilapia donde reportaron valores de 4,35.

En cuanto la acidez titulable, en este estudio se presentaron valores inferiores a 4,0 lo que permite una apropiada hidrólisis puesto que a un $\mathrm{pH}$ por debajo de 4,0 produce la suficiente acidez para impedir la proliferación de microrganismos indeseables que afecta la calidad de los hidrolizados (Hoyos et al,. 2018) como sucedió en este estudio al no presentar recuentos de microorganismos. Los resultados encontrados en el presente estudio fueron superiores a los citados por Perea et al. (2017) en ensilaje de residuos de trucha para alimentación animal en el que encontraron valores 3,10; y a los presentados por Bringas et al. (2018) con ensilaje fermentado de subproductos de tilapia en el cual citaron valor de 2,43.

Se observó que el hidrolizado de vísceras de cerdo presentó el valor más bajo de consistencia debido probablemente a la estructura de las vísceras, las cuales presentaron mayor dureza a pesar del proceso de molienda y al contenido de grasas saturadas que ostentan una consistencia solida principalmente, por el contrario, para el hidrolizado de vísceras de trucha, la consistencia fue elevada, posiblemente por la rápida acción de enzimas proteolíticas presentes en las vísceras, debido a que es una especie de hábito alimenticio carnívora y a que los lípidos presentes son insaturados, lo cual hace que sean mayoritariamente líquidos.

\section{Digestibilidad aparente de la dieta control y de los hidrolizados}

Los resultados obtenidos en las variables de digestibilidad aparente de los nutrientes, energía y asimilación de minerales de la dieta y las mezclas se presentan en el Cuadro 3. Los tratamientos presentaron diferencias significativas $(p<0,05)$ para las variables digestibilidad aparente de la proteína cruda, digestibilidad aparente de la energía bruta, absorción aparente de calcio y absorción aparente de fósforo. 
Cuadro 3. Digestibilidad aparente de los nutrientes, energía y asimilación de minerales de la dieta y las mezclas en Cachama blanca (\%).

\begin{tabular}{|l|c|c|c|c|c|}
\hline \multicolumn{1}{|c|}{ Variable } & T0 $^{1}$ & T1 $^{2}$ & T2 $^{3}$ & T3 $^{4}$ & $\begin{array}{c}\text { ANOVA } \\
\text { Pr }>\text { F }\end{array}$ \\
\hline $\begin{array}{l}\text { Digestibilidad Aparente de la } \\
\text { Materia Seca (DAMS) }\end{array}$ & $91,76 \pm 0,65^{\mathrm{a}}$ & $91,84 \pm 0,78^{\mathrm{a}}$ & $91,41 \pm 0,46^{\mathrm{a}}$ & $92,08 \pm 0,58^{\mathrm{a}}$ & 0,6371 \\
\hline $\begin{array}{l}\text { Digestibilidad Aparente del Extrac- } \\
\text { to de Etéreo (DAEE) }\end{array}$ & $86,51 \pm 2,26^{\mathrm{a}}$ & $88,97 \pm 0,13^{\mathrm{a}}$ & $88,42 \pm 0,13^{\mathrm{a}}$ & $89,24 \pm 0,21^{\mathrm{a}}$ & 0,0692 \\
\hline $\begin{array}{l}\text { Digestibilidad Aparente de la } \\
\text { Proteína Cruda (DAPC) }\end{array}$ & $80,53 \pm 1,45^{\mathrm{b}}$ & $84,20 \pm 0,17^{\mathrm{a}}$ & $82,82 \pm 0,36^{\mathrm{a}}$ & $83,97 \pm 0,12^{\mathrm{a}}$ & 0,0013 \\
\hline $\begin{array}{l}\text { Digestibilidad de la Energía Bruta } \\
\text { (DAEB) }\end{array}$ & $60,92 \pm 2,95^{\mathrm{b}}$ & $68,44 \pm 0,40^{\mathrm{a}}$ & $66,72 \pm 0,24^{\mathrm{a}}$ & $68,70 \pm 0,28^{\mathrm{a}}$ & 0,0007 \\
\hline $\begin{array}{l}\text { Absorción Aparente de Cenizas } \\
\text { (AACEN) }\end{array}$ & $43,01 \pm 2,72^{\mathrm{a}}$ & $43,27 \pm 0,27^{\mathrm{a}}$ & $42,42 \pm 0,39^{\mathrm{a}}$ & $43,84 \pm 0,18^{\mathrm{a}}$ & 0,4761 \\
\hline $\begin{array}{l}\text { Absorción Aparente de Calcio } \\
\text { (AACa) }\end{array}$ & $23,00 \pm 5,08^{\mathrm{b}}$ & $38,69 \pm 0,20^{\mathrm{a}}$ & $38,46 \pm 0,00^{\mathrm{a}}$ & $38,86 \pm 0,10^{\mathrm{a}}$ & 0,0001 \\
\hline $\begin{array}{l}\text { Absorción Aparente de Fósforo } \\
\text { (AAP) }\end{array}$ & $49,53 \pm 0,78^{\mathrm{c}}$ & $54,36 \pm 0,13^{\mathrm{a}}$ & $53,22 \pm 0,26^{\mathrm{b}}$ & $54,49 \pm 0,13^{\mathrm{a}}$ & 0,0001 \\
\hline
\end{tabular}

Letras diferentes en la misma fila, difieren estadísticamente $(p<0,05)$.

${ }^{1}$ Dieta control sin inclusión de hidrolizados de origen animal - T0, ${ }^{2}$ Mezcla con $70 \%$ dieta T0 y $30 \%$ de hidrolizado de vísceras de trucha-T1, ${ }^{3}$ Mezcla con $70 \%$ dieta T0 y $30 \%$ de hidrolizado de vísceras de pollo-T2, ${ }^{4}$ Mezcla con $70 \%$ dieta T0 y $30 \%$ de hidrolizado de vísceras de cerdo-T3.

Pese a que las mezclas suministradas a los animales no se encontraban balanceadas debido a la metodología aplicada, se puede observar que no existen diferencias significativas en la digestibilidad aparente de la materia seca, extracto etéreo y absorción aparente de cenizas en comparación a la dieta control que estaba balanceada (Cuadro 3), indicando que los hidrolizados de origen animal poseen un alto valor nutricional; además, al convertirse en una materia prima para la alimentación animal, se disminuye el impacto negativo en el medio ambiente (Guimarães et al., 2019). Sin embargo, para la digestibilidad aparente de la proteína cruda, energía bruta y absorción aparente del calcio y el fósforo, las mezclas obtuvieron estadísticamente mayores porcentajes de absorción de estos nutrientes por parte de los peces, debido a que estos componentes de origen animal poseen alta calidad nutricional y valor biológico frente a las materias primas vegetales.

El principio de aditividad o método de sustitución es una técnica importante en la valoración de la calidad nutricional de alimentos porque permite conocer específicamente la cantidad de cada uno de los nutrientes y la energía que el animal es capaz de asimilar de una materia prima que se incluye en una dieta, y con ello analizar en detalle el potencial nutricional que presenta. En el Cuadro 4 se presentan los resultados obtenidos de la digestibilidad aparente de nutrientes, energía, y absorción de minerales de los hidrolizados de origen animal (pollo, cerdo y trucha) obtenidos mediante el principio de aditividad.

Cuadro 4. Digestibilidad aparente de nutrientes, energía y asimilación de minerales de hidrolizados de vísceras de origen animal en Cachama blanca (\%).

\begin{tabular}{|c|c|c|c|c|}
\hline Variable & HVP & HVC & HVT & $\begin{array}{c}\text { ANOVA } \\
\operatorname{Pr}>\mathrm{F}\end{array}$ \\
\hline Digestibilidad Aparente de la Materia Seca-DAMS & $92,02 \pm 2,6^{a}$ & $90,60 \pm 1,5^{a}$ & $92,85 \pm 1,9^{a}$ & 0,5339 \\
\hline Digestibilidad Aparente del Extracto de Etéreo-DAEE & $94,7 \pm 0,4^{a}$ & $92,88 \pm 0,4^{b}$ & $95,60 \pm 0,7^{a}$ & 0,0001 \\
\hline Digestibilidad Aparente de la Fibra Cruda-DAFC & $41,93 \pm 1,0^{a}$ & $39,13 \pm 1,2^{b}$ & $43,98 \pm 0,9^{a}$ & 0,0001 \\
\hline Digestibilidad Aparente de la Proteína Cruda-DAPC & $92,74 \pm 0,6^{a}$ & $88,15 \pm 1,2^{\mathrm{b}}$ & $91,99 \pm 0,4^{a}$ & 0,0001 \\
\hline Digestibilidad de la Energía Bruta-DAEB & $85,98 \pm 1,3^{a}$ & $80,27 \pm 0,8^{b}$ & $86,85 \pm 0,9^{a}$ & 0,0001 \\
\hline Absorción Aparente de Cenizas-AACEN & $51,08 \pm 0,9^{a}$ & $48,24 \pm 1,3^{b}$ & $52,99 \pm 0,6^{a}$ & 0,0001 \\
\hline Absorción Aparente de Calcio-AACa & $61,68 \pm 0,7^{a b}$ & $60,93 \pm 0,0^{b}$ & $62,25 \pm 0,3^{a}$ & 0,0001 \\
\hline Absorción Aparente de Fósforo-AAP & $60,82 \pm 0,4^{a}$ & $57,04 \pm 0,9^{b}$ & $61,27 \pm 0,4^{a}$ & 0,0008 \\
\hline
\end{tabular}

Letras diferentes en la misma fila, representan diferencias significativas $(p<0,05)$.

${ }^{1}$ Hidrolizado de vísceras de pollo-HVP, ${ }^{2}$ Hidrolizado de vísceras de cerdo-HVC, ${ }^{3}$ Hidrolizado de vísceras de trucha-HVT. 
No se presentaron diferencias significativas en los valores de digestibilidad de la materia seca $(p<0,05)$ de acuerdo al hidrolizado de vísceras de origen animal evaluado (Cuadro 4), sin embargo, se presentaron diferencias significativas para la digestibilidad aparente del extracto etéreo, fibra cruda, proteína cruda, energía bruta y para absorción aparente de cenizas, calcio y fósforo $(p<0,05)$.

La digestibilidad aparente de la materia seca estuvo por encima del $90 \%$ (Cuadro 4), debido a que los hidrolizados presentan un alto contenido de materia seca digestible, lo que se traduce en una cantidad considerable de nutrientes que potencialmente pueden ser aprovechados por el animal. La digestibilidad aparente de la materia seca de subproductos de origen animal es superior a la de materias primas de origen vegetal debido a la presencia de fibra en éstas últimas, la cual no es digerible en los peces Puerta et al. (2017). Los resultados encontrados en el presente estudio para la DAMS, fueron superiores a los citados en Tilapia nilótica (Oreochromis niloticus) por Fontinha et al. (2021) entre 73,8 y 81,4\% con harina de subproductos avícolas y a los referenciados en Cachama blanca por Puerta et al. (2017) 67,37 y $16,03 \%$ con materias primas como Thitonia diversifolia y Cratylia argéntea respectivamente.

La digestibilidad aparente del extracto etéreo estuvo por encima del $92 \%$, encontrándose que los hidrolizados de pollo y trucha fueron superiores al hidrolizado de cerdo (Cuadro 4), debido principalmente a la calidad de ácidos grasos poliinsaturados (oleico y linoleico principalmente) que presentan, los cuales son fácilmente aprovechados por la cachama, debido a los dobles enlaces que poseen (Perea et al., 2017); además, el proceso de hidrólisis modifica las características de los nutrientes haciéndolos más disponibles, en este caso, el contenido de lípidos presentes en el hidrolizado ayuda a reducir la solubilización excesiva de la proteína que permite mejorar su calidad y facilita la estabilidad (Soares et al., 2020). Los resultados obtenidos en la DAEE son superiores a los registrados en dietas con inclusión de harina de subproductos avícolas, obtuvieron una digestibilidad entre 85,67 y 93,33\% por Hekmatpour et al. (2018) en Sparidentex hasta, y a los reportados por Llanes et al. (2019) con ensilaje químico en Tilapia roja (Oreochromis mossambicus x O. niloticus) con $86,5 \%$.

Los coeficientes de digestibilidad aparente de la fibra para los hidrolizados de pollo y trucha (> $41 \%)$ fueron superiores al hidrolizado de cerdo (Cuadro 4); estos valores de DAFC podrían atribuirse a que son subproductos de origen animal los cuales no poseen fibra, el mínimo contenido encontrado se debe a los residuos de alimento (celulosa, hemicelulosa y lignina) que se encontraban en el tracto digestivo de los animales (Puerta et al., 2017), por consiguiente, al realizar el proceso de hidrólisis de las vísceras se facilita el aprovechamiento de la fibra en peces omnívoros como la Cachama blanca (Mendoza et al., 2013).

Los valores de digestibilidad aparente de la proteína cruda son elevados, superiores al $88 \%$, debido a la calidad nutricional del hidrolizado teniendo en cuenta que en el proceso de hidrólisis existe un efecto de ruptura de las proteínas, generando cadenas polipeptídicas de diferente longitud y aminoácidos libres que son fácilmente absorbidos en el intestino proximal de la cachama (López et al., 2015). El hidrolizado de vísceras de cerdo presentó la menor DAPC, debido probablemente a la estructura de las vísceras que presentaron menor consistencia 10,3 $\pm 0,2 \mathrm{~cm} \mathrm{~s}^{-1}$ frente a $17,9 \pm 0,12 \mathrm{~cm} \mathrm{~s}^{-1}$ para el hidrolizado de pollo y $30,0 \pm 0,0 \mathrm{~cm} \mathrm{~s}^{-1}$ para el hidrolizado de trucha (Cuadro 2), lo que pudo generar menor cantidad de aminoácidos y péptidos libres durante el proceso de hidrólisis, disminuyendo la capacidad de un mayor aprovechamiento por la Cachama blanca (Davies et al., 2020). Los resultados obtenidos son superiores a los reportados por Paz et al. (2016) al evaluar la digestibilidad de dietas con harina de hidrolizado de pescado en arawana (Osteoglossum bicirrhossum) en el cual reportan 81,2 \%, a los citados por López et al. (2015) en hidrolizados de vísceras de pescado en alevinos de Cachama blanca (Piaractus brachypomus) con $85 \%$, a los reportados por Javaherdoust et al. (2020) al evaluar proteína hidrolizada de víscera de rainbow trout en el que citan 83-90\% y a los obtenidos por Banze et al. (2017) con ensilado ácido de vísceras de atún en Rhamdia quelen donde reportan $88,12 \%$ para DAPC.

Los valores elevados encontrados en la absorción aparente de cenizas se deben a la utilización de ácidos orgánicos (fórmico) en el proceso de hidrólisis, los cuales mejoran el aprovechamiento de los minerales por el animal, debido a la solubilidad generada por a la acidez, por consiguiente, los altos coeficientes de absorción de cenizas obtenidas en los hidrolizados de pollo y trucha podrían estar relacionados con la menor acidez titulable obtenida (Paz et al., 
2016). Por otro lado, las materias primas con alto contenido de cenizas podrían afectar la digestibilidad de otros nutrientes (proteína) en la dieta, lo que influiría directamente en el crecimiento de los peces, por ello, es importante que el contenido de cenizas en un ingrediente se mantenga inferior al $12 \%$. Los valores de AACEN encontrados en este estudio, son inferiores a los obtenidos por Llanes et al. (2019) en Tilapia roja (Oreochromis mossambicus x $O$. niloticus) alimentadas con ensilaje biológico de residuos pesqueros encontrando valores de $60,85 \%$ y a los obtenidos por Llanes et al. (2011) en Tilapia roja (Oreochromis mossambicus x O. niloticus) alimentados con ensilados químico y biológico de residuos de fileteado de tilapias (60,63 y $62,85 \%$ respectivamente).

Los elevados valores de la absorción aparente del calcio y el fósforo (Cuadro 4), se pueden atribuir al efecto del ácido orgánico presente en los hidrolizados (ácido fórmico), el cual mejoró su disponibilidad por el efecto acidificante que solubilizó los minerales. Los resultados obtenidos son superiores a los reportados por Huan et al. (2018) con dietas combinadas sin harina de pescado mejorando la digestibilidad de tilapia (Oreochromis niloticus $\times$ O. aureus) encontrando valores para la AACa de $36,13 \%$ y de 55,70 \% para la AAP, y similares a los reportados por Llanes et al. (2019) en Tilapias rojas (Oreochromis mossambicus $\times$ O. niloticus) quienes evaluaron crecimiento con dietas semihúmedas a base residuos pesqueros, con valores para la AACa de 51,55\% y de 65,12\% para la AAP.

En Cuadro 5 se puede apreciar la energía digestible aparente obtenida en juveniles de Cachama blanca, a partir de la fórmula establecida (Briones, 2019), resaltando que los hidrolizados de vísceras de animales presentan un alto contenido de energía digestible, la cual se aprovechó entre el 80,3 y $86,9 \%$.

Cuadro 5. Energía Digestible Aparente (EDA) de hidrolizados de vísceras de origen animal en Cachama blanca.

\begin{tabular}{|l|c|c|c|}
\hline \multicolumn{1}{|c|}{ Tratamientos } & $\begin{array}{c}\text { Energía Bruta (Kcal kg-1 } \\
\text { peso seco) }\end{array}$ & $\begin{array}{c}\text { Digestibilidad de } \\
\text { la energía (\%) }\end{array}$ & $\begin{array}{c}\text { Energía digestible Aparente (EDA }{ }^{4} \text { ) } \\
\text { (Kcal kg } \text { peso seco) }^{-1}\end{array}$ \\
\hline $\mathrm{HVP}^{1}$ & $5922,5 \pm 207,7$ & $86,0 \pm 1,3^{\mathrm{a}}$ & $5092,0 \pm 77,9$ \\
\hline $\mathrm{HVC}^{2}$ & $6585,5 \pm 35,5$ & $80,3 \pm 0,8^{\mathrm{b}}$ & $5286,1 \pm 53,1$ \\
\hline $\mathrm{HVT}^{3}$ & $6847,8 \pm 38,1$ & $86,9 \pm 0,9^{\mathrm{a}}$ & $5947,3 \pm 62,9$ \\
\hline
\end{tabular}

Letras diferentes en la misma fila, representan diferencias significativas $(p<0,05)$.

${ }^{1} \mathrm{HVP}$ (Hidrolizados de vísceras de pollo). ${ }^{2} \mathrm{HVC}$ (Hidrolizado de vísceras de cerdo). ${ }^{3} \mathrm{HVT}$ (Hidrolizado de vísceras de trucha). ${ }^{4} \mathrm{EDA}=$ Energía bruta * \% digestibilidad de la energía.

El contenido de energía digestible puede asociarse a las altas concentraciones de ácidos grasos polinsaturados presentes en los hidrolizados, los cuales son más fáciles de digerir que los saturados (Perea et al., 2017), además, en la hidrólisis se generan polipéptidos de diferente longitud de cadena, aminopéptidos y aminoácidos libres, lo que implica que desde el punto de vista energético se optimizan los procesos de asimilación, debido a que se gasta menor energía en el fraccionamiento de la proteína y en producción de enzimas (López et al., 2015). Los datos encontrados fueron superiores a los obtenidos por Llanes et al. (2019) en Tilapia roja (Oreochromis mossambicus $x$ O. niloticus) a base de ensilados de residuos pesqueros $(3.639,42 \mathrm{Kcal} / \mathrm{kg}$ de peso seco) y similares a los citados por Perea et al. (2017) donde evaluaron ensilajes de residuos piscícolas como alternativa para alimentación animal (5239 $\mathrm{Kcal} / \mathrm{kg}$ de peso seco).

\section{CONCLUSIONES}

Los coeficientes de digestibilidad de la materia seca, extracto etéreo y proteína cruda de los hidrolizados de vísceras de pollo, cerdo y trucha fueron superiores al $88 \%$, lo cual demuestra la calidad nutricional de estos y la eficiencia de la Cachama blanca en el aprovechamiento de los nutrientes; además, los mejores hidrolizados de residuos de origen animal encontrados fueron el hidrolizado de vísceras trucha y el hidrolizado de vísceras pollo que no presentaron diferencias significativas entre ellos en la digestibilidad aparente de la materia seca, energía bruta, extracto etéreo, proteína cruda y la absorción de minerales, por consiguiente, pueden ser considerados como materias primas alternativas de alta calidad nutricional para la alimentación de peces. 


\section{AGRADECIMIENTOS}

A la Universidad del Cauca, Facultad de Ciencias Agrarias, grupos de investigación ASUBAGROIN y NUTRIFACA; Ministerio de Ciencia, Tecnología e Innovación 8MINCIENCIAS) por la financiación de proyecto por medio de los recursos provenientes del patrimonio autónomo fondo nacional de financiamiento para la ciencia, la tecnología y la innovación Francisco José de Caldas; a la Asociación Productora y Comercializadora de Productos Acuícolas y Agrícolas de Silvia -(APROPESCA); a las empresas AGRICA S.A y PISCíCOLA SALVAJINA SAT.

\section{REFERENCIAS}

AUSTRENG, ERLAND. Digestibility determination in fish using chromic oxide marking and analysis of contents from different segments of the gastrointestinal tract. Aquaculture, v. 13, n. 3, 1978, p. 265-272. https://doi.org/10.1016/0044-8486(78)90008-X

BANZE, JORGE-FILIPE; OLIVEIRA-DA SILVA, MARIA-FERNANDA; SCHOFFEN-ENKE, DARIANE-BEATRIZ; FRACALOSSI, DÉBORA-MACHADO. Acid silage of tuna viscera: production, composition, quality and digestibility. Boletim do Instituto de Pesca, São Paulo, v. 44 (vol. esp.), 2017, p. 24-34. https://doi.org/10.20950/1678-2305.2017.24.34

BRINGAS-ALVARADO, LORENA; ZAMORANO-OCHOA, ALBERTINA; ROJO-RODRÍGUEZ, JULIANABERENICE; GONZÁLEZ-FÉLIX, MAYRA-LIZETT; PÉREZ-VELÁZQUEZ, MARTÍN; CÁRDENAS-LÓPEZ, JOSÉ-LUIS; NAVARRO-GARCÍA, GERARDO. Evaluación del ensilado fermentado de subproductos de tilapia y su utilización como ingrediente en dietas para bagre de canal. Revista de Ciencias Biológicas y de la Salud Biotecnia, v. 20, n. 2, 2018, p. 85-94. https://doi.org/10.18633/biotecnia.v20i2.604

BRIONES-ZAMBRANO, KEYLA-BENJA. Digestibilidad de ingredientes proteicos y requerimiento de proteína para el paco (Piaractus brachypomus) en la etapa de alevinos [Tesis Mg. Sc. Nutrición]. Lima (Perú): Universidad Nacional Agraria La Molina, 2019, 72 p.

CAMPOS, INÊS; MATOS, ELISABETE; ARAGÃO, CLÁUDIA; PINTADO-ESTEVEZ, MARIA-MANUELA; VALENTE-PINHEIRO, LUÍSA-MARIA. Apparent digestibility coefficients of processed agro?food by? products in European seabass (Dicentrarchus labrax) juveniles. Aquaculture Nutrition, v. 24, n. 4, 2018, p. 1274-1286.

https://doi.org/10.1111/anu.12665

CHO, C.Y.; SLINGER, S.J.; BAYLEY, H.S. Bioenergetics of salmonid fishes: energy intake, expenditure and productivity. Comparative Biochemistry and Physiology, v. 73, n. 1, 1982, p. 25-41. https://doi.org/10.1016/0305-0491(82)90198-5

COLOMBIA. MINISTERIO DE AGRICULTURA Y DESARROLLO RURAL. Cadena de la acuicultura. Bogotá (Colombia): Dirección de cadenas pecuarias, pesqueras y acuícolas, 2020, 4 p.

CORRÊA, CAMILA-FERNANDES; DA SILVA-OLIVEIRA, THAÍS; LEONARDO, ANTÔNIO-FERNANDO; REIS-NETO, RAFAEL-VILHENA; ENKE-SHOFFEN, DARIANE-BEATRIZ. Acid fish silage in the diet of pacu and tambacu reared at cold suboptimal temperature. Pesquisa Agropecuária Brasileira, v. 55, n. e01653, 2020, p. 1-8. https://doi.org/10.1590/s1678-3921.pab2020.v55.01653

DAVIES, SIMON-JOHN; GÜROY, DERYA; HASSAAN, MOHAMED-SHABAN; EL-AJNAF, S.M.; EL-HAROUN, EHAB. Evaluation of co-fermented apple-pomace, molasses and formic acid generated sardine based fish silages as fishmeal substitutes in diets for juvenile european sea bass (Dicentrachus Labrax) Production. Aquaculture, v. 521, 2020, p. 735087.

https://doi.org/10.1111/anu.12969 
DOS SANTOS-CARDOSO, MARJANA; GODOY, ANTONIO-CESAR; OXFORD, JARRED-HUGH; RODRIGUEZ, RÔMULO; DOS SANTOS-CARDOSO, MATHEUS; BITTENCOURT, FABIO; SIGNOR, ALTEVIR; BOSCOLO, WILSON-ROGÉRIO; FEIDEN, ALDI. Apparent digestibility of protein hydrolysates from chicken and swine slaughter residues for Nile Tilapia. Aquaculture, v. 530, 2021, p. 735720. https://doi.org/10.1016/j.aquaculture.2020.735720

DUNCAN, D.B. T tests and intervals for comparisons suggested by the data. Biometrics, v. 31, n. 2, 1975, p. 339-59.

FONTINHA, FILIPA; MAGALHÃES, RUI; MOUTINHO, SARA; SANTOS, RAFAELA A.; CAMPOS, P.; SERRA, CLAUDIA-REIS; AIRES, TIAGO; OLIVA-TELES, AIRES; PERES, HELENA. Effect of dietary poultry meal and oil on growth, digestive capacity, and gut microbiota of gilthead seabream (Sparus aurata) Juveniles. Aquaculture, v. 530, n. 2020, 2021, p. 735879. https://doi.org/10.1016/j.aquaculture.2020.735879

GUIMARÃES, CRISTIANE-CUNHA; SILVA, ANTONIO-JOSÉ-INHAMUNS-DA; GUIMARÃES-CRUZ, FRANKGEORGE; FERREIRA-RUFINO, JOÃO-PAULO; SILVA, ANDRÉ; COSTA, VALCELY. Digestibility and Physicochemical characteristics of tambaqui waste biological silage meal included in commercial layer diets. Brazilian Journal of Poultry Science, v. 21, n. 3, 2019, p. 1-6. https://doi.org/10.1590/1806-9061-2018-0869

HEKMATPOUR, FATEMEH; KOCHANIAN, PREETA; MARAMMAZI, JASEM, G.H.; ZAKERI, MOHAMMAD; MOUSAVI, SEYED-MOHAMMAD. Inclusion of poultry by-product meal in the diet of Sparidentex hasta: effects on production performance, digestibility and nutrient retention. Animal Feed Science and Technology, v. 241, 2018, p. 173-83. 10.1016/j.anifeedsci.2018.02.010

HIDALGO, VÍCTOR; VALERIO, HENRY. Digestibilidad y energía digestible y metabolizable del gluten de maíz, hominy feed y subproducto de trigo en cuyes (Cavia porcellus). Revista de Investigaciones Veterinarias del Perú, v. 31, n. 2, 2020, e17816. http://dx.doi.org/10.15381/rivep.v31i2.17816

HOYOS-CONCHA, JOSÉ-LUÍS; VILLADA-CASTILLO, HÉCTOR-SAMUEL; FERNÁNDEZQUINTERO, ALEJANDRO; BONILLA-MÉNDEZ, JEIMMY-ROCÍO. Chemical Characterization of Hydrolyzed Protein Meal Obtained from Trout (Oncorynchus mykiss) By-Products Silage. Indian Journal of Science and Technology, v. 11, n. 16, 2018, p. 1-13. 10.17485/ijst/2018/v11i16/118634

HUAN, DIANYU; LI, XIAOQIN; KABIR-CHOWDHURY, MOHIUDDIN-AMIRUL; YANG, HANG; LIANG, GAOYANG; LENG, XIANGJUN. Organic acid salts, protease and their combination in fish mealfree diets improved growth, nutrient retention and digestibility of tilapia (Oreochromis niloticus $\times 0$. aureus), Aquaculture Nutrition, v. 24, n. 18, 2018, p. 1813-1821. http://doi.org10.1111/anu.12820

JAVAHERDOUST, SHAGHAYEGH; YEGANEH, SAKINEH; KERAMAT-AMIRKOLAIE, ABDOLSAMAD. Effects of dietary visceral protein hydrolysate of rainbow trout on growth performance, carcass composition, digestibility and antioxidant Enzyme in Juvenile Oncorhynchus mykiss. Aquaculture Nutrition, v. 26, n. 1, 2020, p. 134-44. https://doi.org/10.1111/anu.12975

KJELDAHL-THORSAGER, JOHAN-GUSTAV-CHRISTOFFER. Neue Methode zur Bestimmung des Stickstoffs in organischen Körpern. Zeitschrift für analytische Chemie, v. 22, 1983, p. 366-382. https://doi.org/10.1007/BF01338151

LLANES-IGLESIAS, JOSÉ-ENRIQUE; TOLEDO-PÉREZ, JOSÉ; SAVÓN, LOURDES; GUTIÉRREZ, ODILIA. Evaluación nutricional de ensilajes de residuos pesqueros para la alimentación de tilapias rojas (Oreochromis mossambicus x O. niloticus). Revista Cubana de Investigaciones Pesqueras, v. 28, n. 2, 2011, p. 15-20.

LLANES-IGLESIAS, JOSÉ-ENRIQUE; TOLEDO-PÉREZ, JOSÉ; PORTALES, ANAISY; SARDUY, LUCIA. Reemplazo parcial de harina de pescado por ensilado cárnico en dietas extrusadas para Clarias gariepinus. Cuban Journal of Agricultural Science, v. 51, n.1, 2017, p. 71-77. 
LLANES-IGLESIAS, JOSÉ-ENRIQUE; PORTALES-GONZÁLEZ, ANAISY; TOLEDO-PÉREZ, JOSÉ. Posibilidades del ensilado cárnico en dietas extrusadas para Clarias gariepinus. Revista Cubana de Investigaciones Pesqueras, v. 36, n. 2, 2019, p. 68-72.

LÓPEZ-MACÍAS, JORGE; SALAZAR-RAMOS, DIANA-OMAIRA; IZQUIERDO-ROSERO, CESAR-ANDRÉS. Coeficientes de digestibilidad de la harina de hidrolizado de vísceras de Cachamba Blanca (Piaractus brachypomus Cuvier 1818), usada como fuente de proteína en la alimentacion de sus alevinos. Acta Biológica Paranaense, v. 44, n. 1, 2015, p. 7-16. https://doi.org/10.5380/abpr.v44i1-2.43731

MENDOZA, MIGUEL-ÁNGEL; COMAS-CORREDOR, JAIR; ROMERO-HURTADO, CLARA-STEFANY. Estudio histológico del sistema digestivo en diferentes estadios de desarrollo de la cachama blanca (Piaractus brachypomus), Revista Médico Veterinario, v. 25, 2013, p. 21-38. https://doi.org/10.19052/mv.2296

MONTOYA-MEJÍA, MAGNOLIA; GARCÍA-ULLOA, MANUEL; HERNÁNDEZ-LLAMAS, ALFREDO; NOLASCOSORIA, HÉCTOR; RODRÍGUEZ-GONZÁLEZ, HERVEY. Digestibility, growth, blood chemistry, and enzyme activity of juvenile Oreochromis niloticus fed isocaloric diets containing animal and plant byproducts. Revista Brasileira de Zootecnia, v. 46, n. 12, 2017, p. 873-882. https://dx.doi.org/10.1590/s1806-92902017001200001

-OZYURT, CANER; KULEY BOGA, ESMERAY; OZKUTUK, ALI SERHAT; UCAR, YILMAZ; DURMUS, MUSTAFA; OZYURT, GÜLSÜN. Bioconversion of discard fish (Equulites klunzingeri and Carassius gibelio) fermented with natural lactic acid bacteria; the chemical and microbiological quality of ensilage. Waste and Biomass Valorization, v. 11, 2020, p. 1435-1442. https://doi.org/10.1007/s12649-018-0493-5

PAZ A., MARIO; MENESES, JOHN; LÓPEZ, JORGE. Digestibility of diets with flour fish silage for the growing of arawana (Osteoglossum bicirrhossum). Revista MVZ Córdoba, v. 21, n. 1, 2016, p. 5177-5188.

PEREA-ROMÁN, CRÍSPULO; HOYOS-CONCHA, JOSÉ-LUÍS; GARCÉS-CAICEDO, YENY-JUDITH; MUÑOZARBOLEDA, LUZ-STELLA; GÓMEZ-PEÑARANDA, JOSÉ-ADER. Evaluación de procesos para obtener ensilaje de residuos piscícolas para alimentación animal. Ciencia en desarrollo, v. 8, n. 2, 2017, p. 47-58. https://doi.org/10.19053/01217488.v8.n2.2017.6174

PEREA-ROMAN, CRÍSPULO; GARCÉS-CAICEDO, YENY-JUDITH;MUÑOZ-ARBOLEDA, LUZ-STELLA; HOYOSCONCHA, JOSÉ-LUÍS; GÓMEZ-PEÑARANDA, JOSÉ-ADER. Valoración económica del uso de ensilaje de residuos piscícolas en la alimentación de Oreochromis spp. Biotecnología en el sector agropecuario y agroindustrial, v. 16, n. 1, 2018, p. 43-51.

http://dx.doi.org/10.18684/bsaa.v16n1.623

PUERTA-RICO, LUIS-FERNANDO; GARCÍA-GONZÁLEZ, JOSÉ-JAIME; PARRA-SUESCÚN, JAIME-EDUARDO; PARDO-CARRASCO, SANDRA-CLEMENCIA. Coeficientes de digestibilidad aparente de Thitonia diversifolia y Cratylia argéntea en cachama blanca y efectos sobre las vellosidades intestinales, Revista U.D.C.A Actualidad y Divulgación Científica, v. 20, n. 2, 2017, p. 375-383. https://doi.org/10.31910/rudca.v20.n2.2017.395

RAMÍREZ-MORA, JOSÉ-NOBEL; USECHE, MANUEL-CRISOSTOMO; NIÑO, PEDRO-ALEXANDER; LEAL, CARLOS; BALDISSEROTTO, BERNARDO. Production of cachama reciprocal hybrids in earth ponds. Ciência Rural, v. 49, n. 11, 2019, p. 1-6. https://doi.org/10.1590/0103-8478cr20180113

SOARES, MARIANA; COSTA-REZENDE, PRISCILA; MACHADO-CORRÊA, NICOLE; SOUSA-ROCHA, JAMILLY; ARANA-MARTINS, MATEUS; COSTA-ANDRADE, THAÍS; MACHADO-FRACALOSSI, DÉBORA; NASCIMENTO-VIEIRA, FELIPEDO. Protein hydrolysates from poultry by-product and swine liver as an alternative dietary protein source for the Pacific white shrimp. Aquaculture Reports, v. 17, n. 2020, p. 100344.

https://doi.org/10.1016/j.aqrep.2020.100344 
TANUJA, SOMARAJAN; KUMAR-NAYAK, SUJIT; NAYAK, S.K. Effect of dietary intake of acid ensiled fish waste on the growth, feed utilization, hematology and serum biochemistry of rohu Labeo rohita, (Hamilton, 1822) fingerlings. Indian Journal of Animal Research, v. 51, n. 3, 2017, p. 501-505. 10.18805/ijar.vOiOf.3792

UNITED STATES OF AMERICA. ASSOCIATION OF OFFICIAL ANALYTICAL CHEMISTS (AOAC). Official methods of analysis of the Association of Official Analytical Chemists, Method 920.39, 934.01 y 942.05. 15th ed. Arlington (United States of America): Helrich, Kenneth 1990, p. 30-64.

UNITED STATES OF AMERICA. ASSOCIATION OF OFFICIAL ANALYTICAL CHEMISTS (AOAC). Official methods of analysis of the Association of Official Analytical Chemists International, Method 985.35.18 th Ed. Revision \# 1. Gaithersburg (United States of America ): AOAC International, 2005, 15 p.

WEI, YULIANG; LIANG, MENGQING; XU, HOUGUO. Fish protein hydrolysate affected amino acid absorption and related gene expressions of igf-1/akt pathways in turbot (Scophthalmus maximus). Aquaculture Nutrition, v. 26, n. 1, 2020, p. 145-55.

https://doi.org/10.1111/anu.12976 